\title{
PULSE WIDTH MODULATION TECHNIQUE FOR THE SPEED CONTROL OF M-PHASE AC MOTORS
}

\author{
EGWAILE JOEL OSARUMWENSE*, ORIAHI MATTHEW \\ Department of Electrical/Electronic Engineering, Faculty of Engineering, University of \\ Benin, PMB 1154, Benin City, Edo State, Nigeria
}

\begin{abstract}
Thyristors are now widely used in many power electronics and motor driven applications and all the known methods of control are nothing but variations of either the phase angle firing control (PFC) or the pulse width modulation control (PWM). Each of these methods has its own benefits and disadvantages, but the pulse width modulation control method is, perhaps, by far, the most effective and costly method. Since PWM differs from phase firing control (PFC) in that the control action of PWM takes place only during the time of the firing pulse, this research seeks to develop a combination firing package that maximizes the benefits of the two methods. At first a thyristor is configured as a PNP-type power transistor latch with two ordinary NPN bipolar switching transistors. The power transistor is switched on by zero crossover firing and then switched off by phase angle delay firing. The performance of the model was evaluated and the dynamic characteristics of the motor, such as speed, current, voltage and the total harmonic distortion were carried via simulation. The results shows that by using the Modified PWM firing technique the speed of an m-phase induction motor can be controlled more effectively and reliably. The circuit is easy to implement and cost effective and may be patented and made available for commercial use.
\end{abstract}

Keywords: Pulse Width Modulation, Phase angle delay, Bipolar switching

\section{INTRODUCTION}

Adjustable drives allow industrial processes on a production line to operate at different speeds for different products in order to compensate for changing process variables; allow for slow operation for setup purposes and adjust the rate of production for better efficiency. Until very recently, such drives were almost exclusively in the domain of DC motors combined with various configurations of AC-to-DC converters depending on the application.

The speed of a DC motor may be controlled simply by varying the voltage applied to its armature winding and the torque is proportional to the square of the armature current. AC motors, on the other hand, have speed capabilities only when operating from variable frequency sources. The torque is proportional to the square of the applied voltage, and the slip, and speed control is achieved by varying the magnitude of the applied voltage and/or its frequency, and for each setting of these, the speed is essentially independent of the load.

AC motors often feature several advantages over their DC counterparts. They are uncomplicated and rugged in construction, resulting in lower maintenance costs and improved reliability, and their performance characteristics can be adjusted to fit a number of different operating conditions by relatively simple design changes [1]. However, the control capabilities available with these drives using conventional switching devices is cumbersome, that for

\footnotetext{
${ }^{*}$ Corresponding author, email: joel.egwaile@ uniben.edu

(C) 2019 Alma Mater Publishing House
} 
the most part, it is more expedient to operate them from constant frequency sources and obtain variable speed by a mechanical or electro-mechanical drive systems while the speed of the motor itself remains constant [2].

Nowadays, however, with improvements in digital technology, all the known methods of controlling the speed of AC motors using electronic switching devices, are nothing but variations of either the phase angle delay control (PFC) or the pulse width modulation control (PWM), each with its own benefits and disadvantages. Pulse width modulation allows us to have control over the percentage ON and OFF duty cycle of the applied voltage. With PWM, the speed control of an induction motor has been shown to be more than a match for DC drives [3, 4]. This research is primarily concerned with the phase angle control of pulse width modulation.

\subsection{Review of speed control strategies}

Controlling the speed of an induction motor with a semiconductor switch gives the benefits of smooth torque at low speeds and complete speed control from zero up to the nominal rated speed of the motor with only small potentiometer adjustments. There are two main control strategies by which the speed of an AC motor may be varied using a semiconductor switching device. These are:

- The phase angle firing scheme (PFC);

- The pulse width modulation firing scheme (PWM).

Many variations of each of these have been published and all have the same underlying commonality. Here is a review of these strategies.

\subsubsection{The PFC firing scheme}

One of the earliest methods used to generate PFC switching signals utilizes a device in which the system forms the phase angle delay itself. Here, a bistable circuit is utilized in such a manner that its dwell time for one state is controlled by a trigger circuit oscillator whose delay time is in surn a function of the applied voltage [5]. In an alternative system suggested in a paper by Abramowitz, [6], the driving function was separated from the phase angle delaying function. The modulating signal is compared with a reference dc voltage in a comparator and delayed firing pulses are obtained. Sen et all, [7] have proposed a model in which the modulating signal is first transformed into square pulses in a first compactor before being integrated.

\subsubsection{The PWM firing scheme}

PWM pulses are generated when a high frequency carrier modulates a low frequency analogue signal in a comparator. By changing the percentage duty cycle of the applied voltage, the average power delivered to an electric motor, and hence the speed, of the motor can be varied accordingly. Typically, the analog signal is connected to the inverting terminal of the comparator while the carrier is connected to the non-inverting terminal The carrier need not be symmetrical, although the linearity of the waveform is important [3].

The most common method of generating PWM signals is the Naturally Sampled Sine-Triangle scheme, in which a high frequency equal-sided triangle wave is modulated with a low frequency. Lu $\mathrm{X}$ et al [8] presented Volts/frequency scheme based on this principle. This is the most common application of the PWM firing scheme. The main switching devices are the MOSFET and each MOSFET has a freewheeling diode connected in antiparallel. The ratio of volts to frequency is kept constant. This ratio, often referred to as Volts-Per-Hertz (V/Hz), is controlled by an inverter. By a mutual control of the supply voltage as well as the as well as the frequency of inversion, the speed of an induction motor can be made to change or vary over wide values under different load conditions.

The cosine firing scheme is a variation of the PWM control strategy proposed by Sen T, et al, [7]. Here, the analogue signal is integrated into a cosine wave and then compared with a d.c. reference voltage in a comparator (or comparators) to produce PWM pulses. The output of the comparator is fed to a mono-shot unit to produce pulses of small width to drive a bistable flip flop. The flip flop produces complimentary square pulses during which window space periods external triggering pulses are gated to the respective SCRs.

Peter Geno et. al [9] presented cosine wave crossing control is used for firing circuit. The advantage of this scheme is that the output voltage is proportional to the control voltage. He has included various protections like shot circuit, under voltage and over voltage etc. The main purpose of this project is to design an efficient, simple, robust and economical control circuit. 
Ilango B. et al. [3] presented the firing circuit for the three phase SCR bridge rectifiers used for industrial applications. It is a compact scheme using minimum integrated circuit components which gives a fast response for triggering angle correction and gives a full range control of voltage.

The Space Vector modulation strategy, which is often claimed to be a completely different approach to modulation, is really, according to Lipo T. et al, [2], only a variation of regular sampled PWM which specifies the same switched pulse widths but only places them a little differently in each carrier interval. The field oriented control strategy (FOC) differs from the traditional vector product due to its ability to separate and independently control (or regulate) the motor flux and frequency [10].

The microcontroller speed control scheme is an on or off closed loop control system that takes control action based on digital inputs and feedback. A programmable logic controller (PLC) uses logic gates to process its inputs, while an on-board microprocessor (PDI) accepts a user input and takes control action based on the sum of three terms: a proportional $\mathrm{r}$, a derivative term, a derivative and the integral of the error, to monitor the output motor characteristics and adjust the conduction angle of the SCR accordingly to get the desired response [11].

Tang Pei-Chong et al, [12], presented a microprocessor-based firing scheme. Together with software algorithm in microprocessor, the digitized ac power signals are used to find the correct firing output signals. This scheme uses less hardware components and has higher dynamic performance in four-quadrant operation.

The aim of this research is to develop a PWM speed controller that drives the pulse width modulation process by creating a thyristor that can be switched ON and OFF like a transistor. The circuit was designed, simulated and its performance evaluated.

\section{EXPERIMENTAL SETUP}

\subsection{The proposed firing scheme}

In principle, there is need for a controlled device that can be switched on at zero voltage crossing and then switched off after a time delay. There is no model of an AC switch to simulate this behavior. The conventional thyristor is essentially a controlled diode. It can only be switched on after a phase angle delay and switches off at zero voltage crossing. So we created a transistor model of an SCR and configured it as a transistor latch, as shown in the block diagram of Figure 1a, for easy controllability. As can be seen from the provisional waveform shown in Figure 1b, there can be no switching transients and the larger the area under the curve, the more is the power delivered.

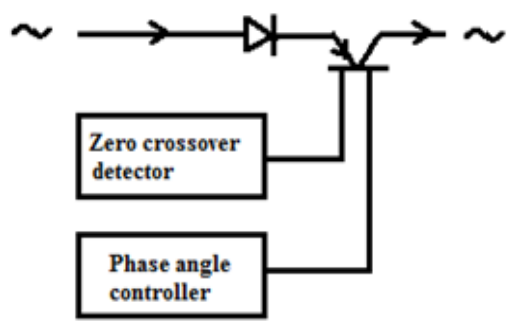

a) Block diagram

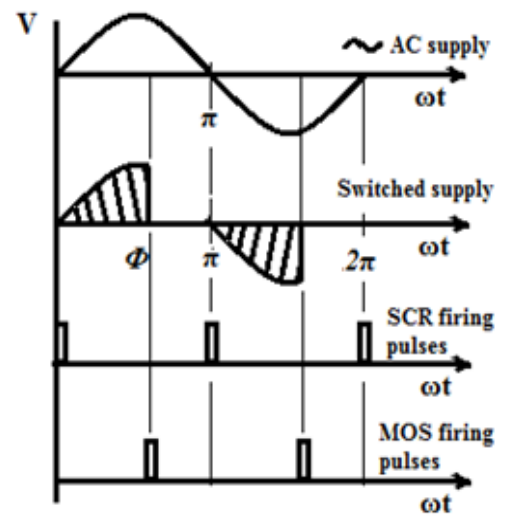

b) The provisional waveforms

Fig. 1. The system concept and provisional waveform.

The transistor latch functions like a controlled thyristor. It is configured with a P-MOS power transistor as the main switching element and two ordinary NPN bipolar transistors as the auxiliary switching elements, as shown in Figure 2. A small current injected into the base terminal of the first NPN transistor is all that is required to switch it on. Once switched on, the power transistor latches on to itself, just like a thyristor, but can be turned off switched off as easily anytime in the power cycle when the second transistor is pulsed. The p-MOS transistor is 
preferred over the PNP transistor because it has no junction in its main current path, which makes it to be of very small size.

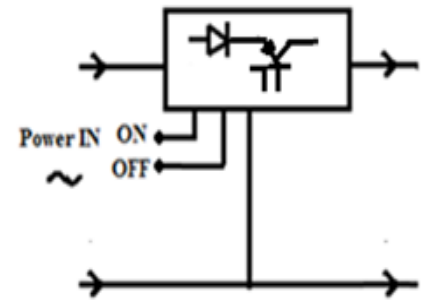

a). Block diagram

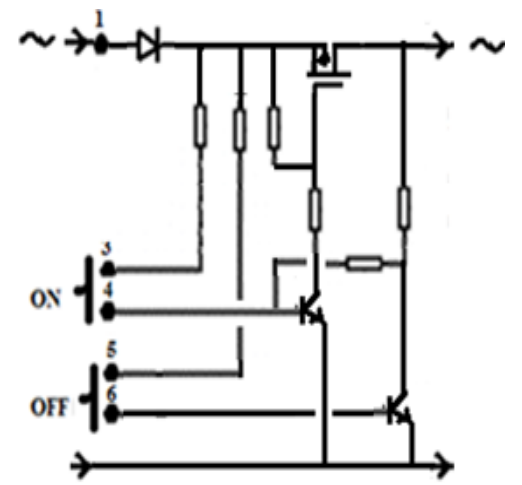

b). Circuit Diagram

Fig. 2. Implementation of transistor latch.

\subsection{The basic block diagram and its circuit description}

The provisional Block diagram for the drive is given in Figure 3. At the front end of the block diagram is the power supply and synchronizing unit which provides the synchronizing voltage, Vsync, as well as the standard DC power supply voltage, Vcc, down to the single 5V DC supply used for IC logic, from a 220/12V $50 \mathrm{~Hz}$ transformer and rectifiers. Without synchronization, the firing points of the triggering circuit will not be coincident with the power supply and firing error will occur.

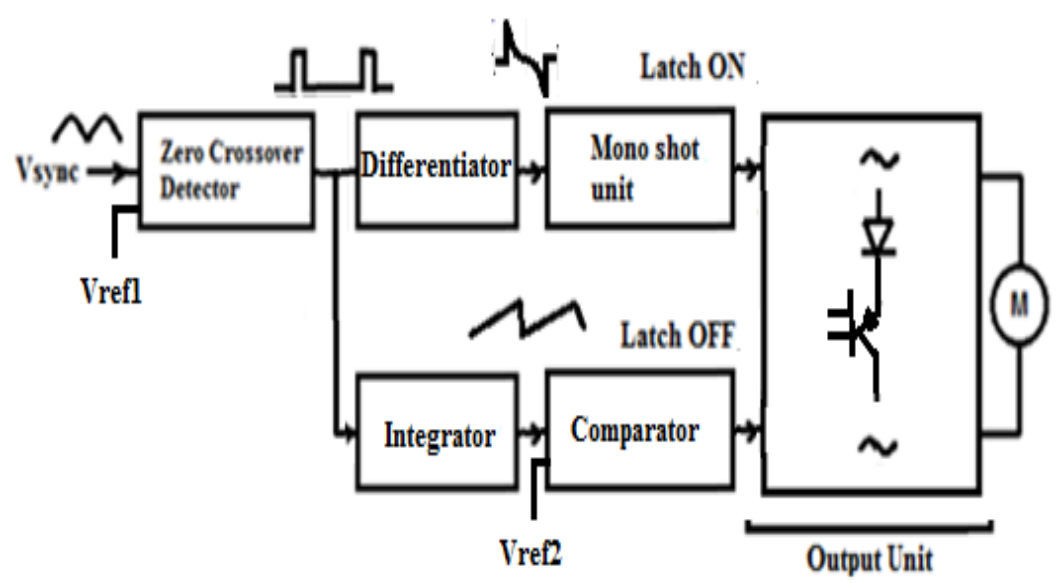

Fig. 3. The provisional block diagram.

\subsubsection{The modified PWM speed controller circuit}

Vsync is fed into the Zero crossover detector (ZCD), which establishes the window space area for PWM. Vsync is metered by potentiometer Vref1 into a comparator (CMP1), as shown in Figure 4, which outputs zero volts everywhere except at the voltage crossover points. We then invert this signal and pass it through a differentiator connected to a mono shot unit, which provides a fixed pulse of constant amplitude to switch on the latch. The mono shot is uniquely implemented by a comparator as shown. The pulse is developed from the differentiated voltage across the resistor at its input terminal. Pulse delay is achieved by adjusting the reference voltage at the input terminal of the comparator CMP1. Simultaneously, the output of the comparator is fed to an integrator which realises the time function. The output of the integrator then goes to the comparator, CMP3, where voltage inversion takes place. The output of the comparator will then remain high until the circuit resets, which ensures that the latch stays off until the circuit resets. 


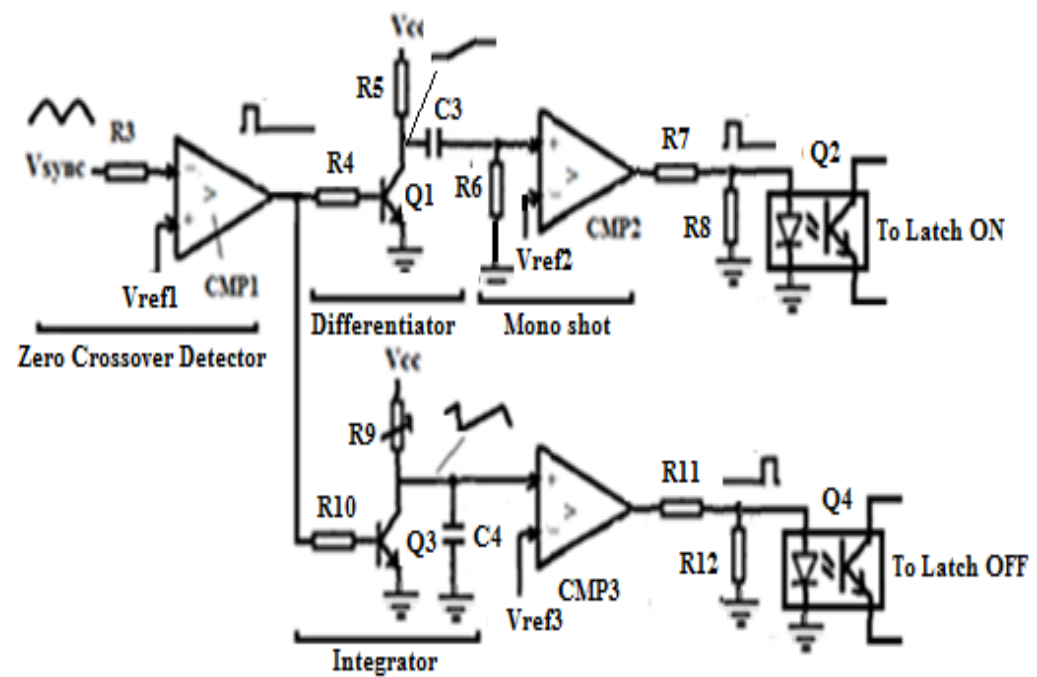

Fig. 4. The modified PWM speed controller.

\subsubsection{The output circuit}

The output circuit is designed to meet the twin objectives of strengthening the trigger pulses to drive the transistor as well as provide proper isolation between the low voltage driver circuits and the supply voltage. Opto transistor isolators are used as solid state relays to control the high current/voltage load based on the operation of a low power input LED circuit. A transistor latch is connected in each line of the power supply as shown in Figure 5. Each latch will conduct depending on which emitter is positive with respect to its collector when the trigger pulses arrive. The steering diodes D1, D2, D3 and D4 are for required for a full wave operation.

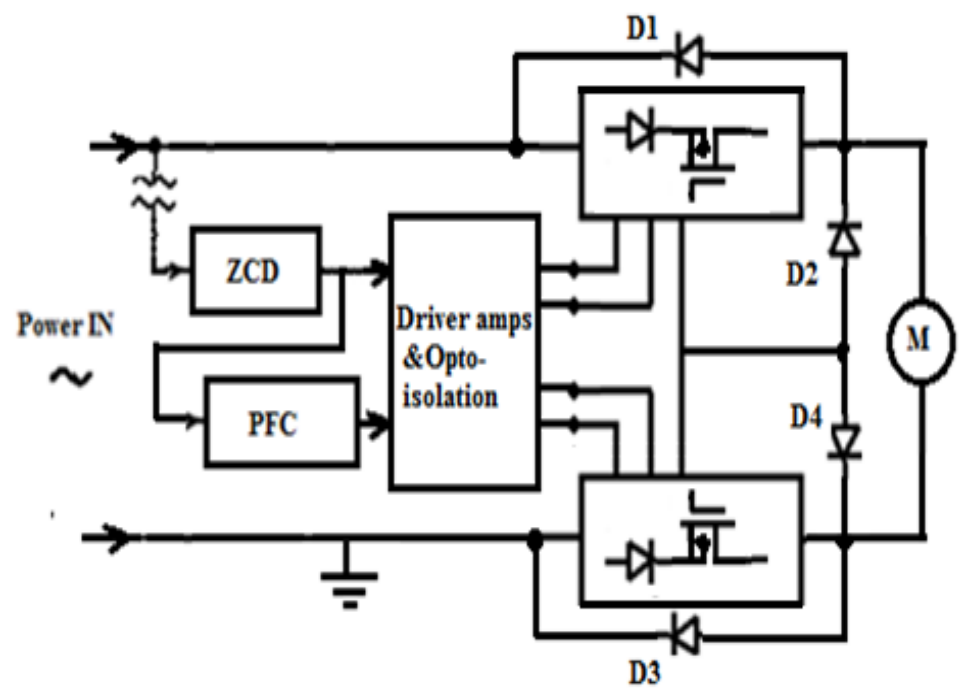

Fig. 5. Output circuit of single phase load.

\subsection{Modeling an inductive load switching device}

Controlling the speed of an induction motor requires that the angle of conduction of the switching thyristor be known. We begin by deriving the model equation of an induction motor in terms of slip. After a mathematical analysis, the control parameters can be found and the speed variation/control plots could then be represented by a phase control circuit that can be implemented on a circuit board.

The current through an inductive R-L load due to an alternating voltage, $v_{s}=V_{s m} \sin \omega t$ is given by the equation: 


$$
L \frac{d}{d t} i+R i=V_{s m} \sin \omega t
$$

From which we get:

$$
i_{T}=\frac{V_{S m}}{|Z(\omega)|}\left[\sin (\omega t-\emptyset)-\sin \emptyset e^{-t /(L / R)}\right] ; \quad \varnothing \leq \omega t \leq \pi
$$

Which indicates a waveform of repeated transients,

Where $\emptyset=\tan ^{-1}(\omega L / R)$

And $\left.|Z(\omega)|=\sqrt{[} R^{2}+(\omega L)^{2}\right]$, [14].

As $\omega L / R$ increases, the exponential term decays more slowly and the current equation given in (2) may be written simply as:

$$
i_{T}=\frac{V_{s m}}{|Z(\omega)|}[\sin (\omega t+\partial)-\sin (\partial)] ; \quad 0 \leq 0 \omega t+\partial
$$

Where: $\partial=\varnothing\left(\frac{\omega \mathrm{L}}{\mathrm{R}}\right)$.

The presence of the angle $\partial$, means that there is an angle of conduction for which the current is continuous and the thyristor cannot be controlled. Thus controlling the speed of an induction motor with a thyristor becomes essentially an exercise in controlling the firing phase angle of the thyristor. The relationship between $\partial$ and $\emptyset$ can be evaluated by plotting the curves $\partial=(w L / R) \emptyset$ on the same graphic window for varying values of $\omega L / R$.

\subsection{Modeling the induction motor}

An electric motor takes in electrical power and delivers it at the shaft as mechanical power. The power that is read on the nameplate of a motor includes the power factor term, which mirrors the efficiency of the energy conversion. Typically, the nameplate provides the power factor of the motor for its rated power and speed at a power factor of 0.8 [13]. Using the trigonometrical identity:

$$
\cos ^{2} \emptyset+\sin ^{2} \emptyset=1
$$

we have:

$$
\sin \emptyset=\omega L /|Z(\omega)|=0.6,
$$

so that:

$$
\tan \emptyset=\omega L / R=\frac{0.6}{0.8}=0.75,
$$

where:

$$
\begin{gathered}
\cos \emptyset=R /|Z(\omega)|=0.8 \text { and } \\
|Z(\omega)|=\sqrt{\left[R^{2}+(\omega L)^{2} .[25] .\right.}
\end{gathered}
$$

At no load, the speed is near synchronous and the power factor is near unity. $\omega L / R$ increases the slip and the power factor falls. The difference is usually relatively small. Assuming a worst case drop of 0.75 , down from 0.8 ,

$$
\emptyset=\cos ^{-1} 0.75=41.4^{\circ},
$$

so that 


$$
\omega L /_{R}=\tan 41.4^{\circ}=0.88
$$

and $\partial=30^{\circ}$.

Then, for a test motor with nameplate data of $1.5 \mathrm{Hp}, 220$ Volts, $6.25 \mathrm{amps}$ and $1500 \mathrm{RPM}$ at $50 \mathrm{~Hz}$,

$$
\mathrm{Z}(\omega)=\frac{V_{s}^{2}}{0.75 P_{\text {in }}}=34,2 \Omega
$$

so that:

$$
R_{S}=34,2 \cos 41.4^{\circ}=26.4 \Omega
$$

and

$$
L_{s}=\frac{34,2}{\omega} \sin 41.4^{\circ}=0.07 \mathrm{H}
$$

\subsection{Designing the Speed Controller Circuit}

The $30^{\circ}$ conduction angle obtained in section 2.4 requires that the firing pulse be delayed by a minimum of $3.2 \mathrm{~ms}$. (The period of one half cycle of a $50 \mathrm{~Hz}$ waveform is 10 milliseconds). This is realized by adjusting the dc reference voltage at the positive terminal of the zero cross over detector. The remaining time delay period of $6.8 \mathrm{~ms}$ is set by the R7C4 integrator of the phase angle controller. Using the half-voltage charging curve expression

$t=0.7 R C$, we get

$$
R C=\frac{6.8 \times 10^{-3}}{0.7}=0.0097
$$

and if we take, $C=C 3=0.1$ uf, we get:

$$
R_{\text {max }}=\frac{0.0097}{0.1 \times \times 10^{-6}}=97 \mathrm{k} \Omega
$$

which we split into a small fixed trimmer resistor of $10 \mathrm{k} \Omega$ and a variable $100 \mathrm{k} \Omega$ potentiometer.

Finally, we now assembled an electronic circuit with the various circuit components and came up with the Bringing the various sections of the system together results in the single phase full wave circuit shown in Figure 6.

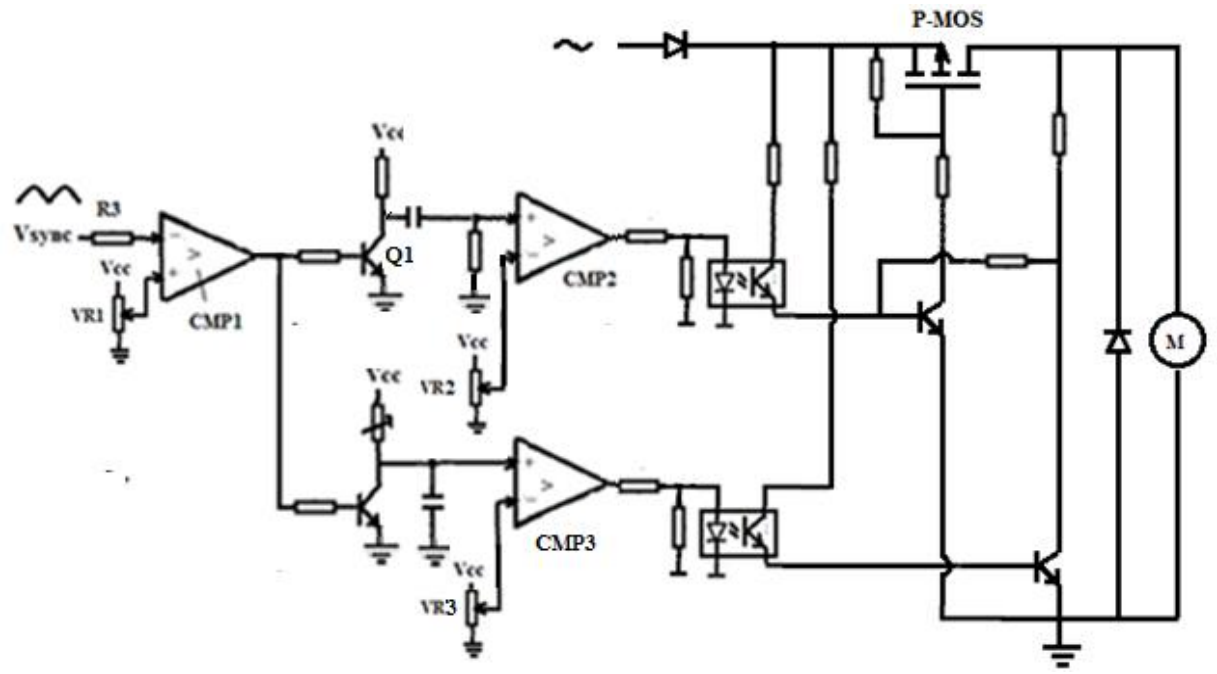

Fig. 6. The single phase half wave modified PWM controller. 


\section{RESULTS AND DISCUSSION}

\subsection{Determination of steady state operating characteristics}

A DC Bias point analysis of a p-mos transistor was carried out to determine its steady state operating characteristics, using the PSpice computer simulation program (version 9.1). We swept a 220 volts DC across the gate terminal of the p-mos part, using a potentiometer, as shown in Figure7. The simulation result shows that the transistor is fully conductive when the potential divider ratio is between 0.2 and 0.6 . We chose 0.5 , or 50 volts.
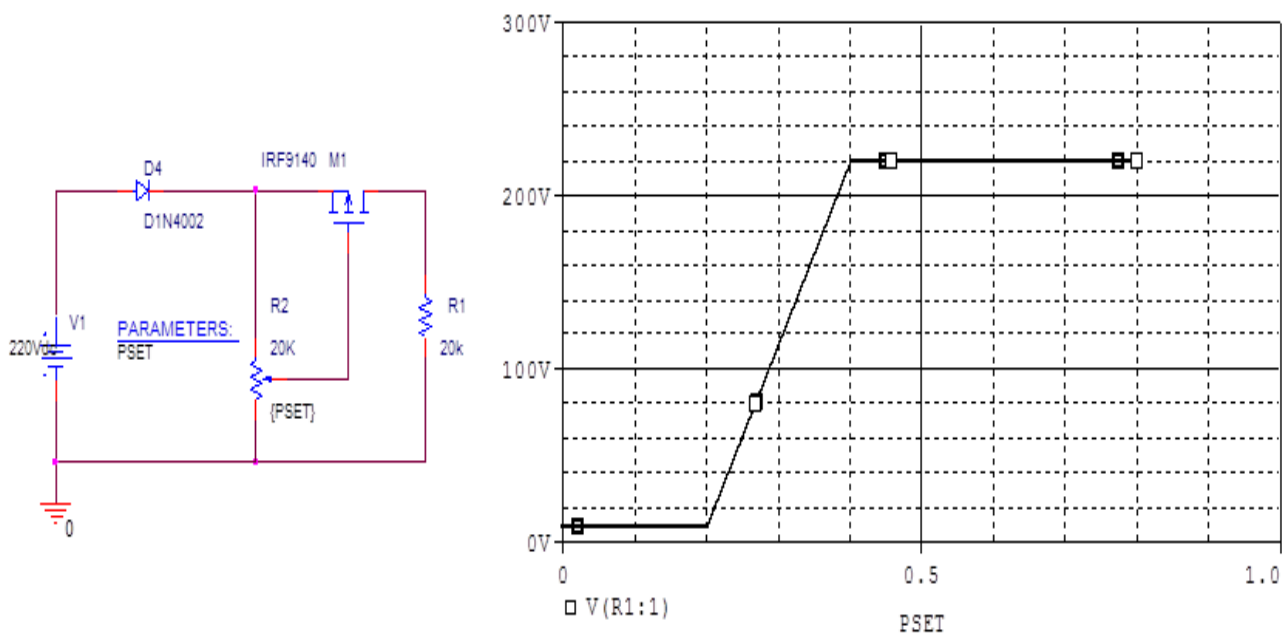

Fig. 7. DC bias point analysis of p-mos transistor.

Next, a switching circuit was created to include an op to coupler and NPN bipolar transistors as the switching elements, as shown in Figure 8, and did a 6 volts DC sweep across the base of the opto transistor to establish the operation of the latch. The simulation result shows this would occur when the ratio of the potentiometer is between 0.4 and 1.0 .5 , or 3 volts was chosen.
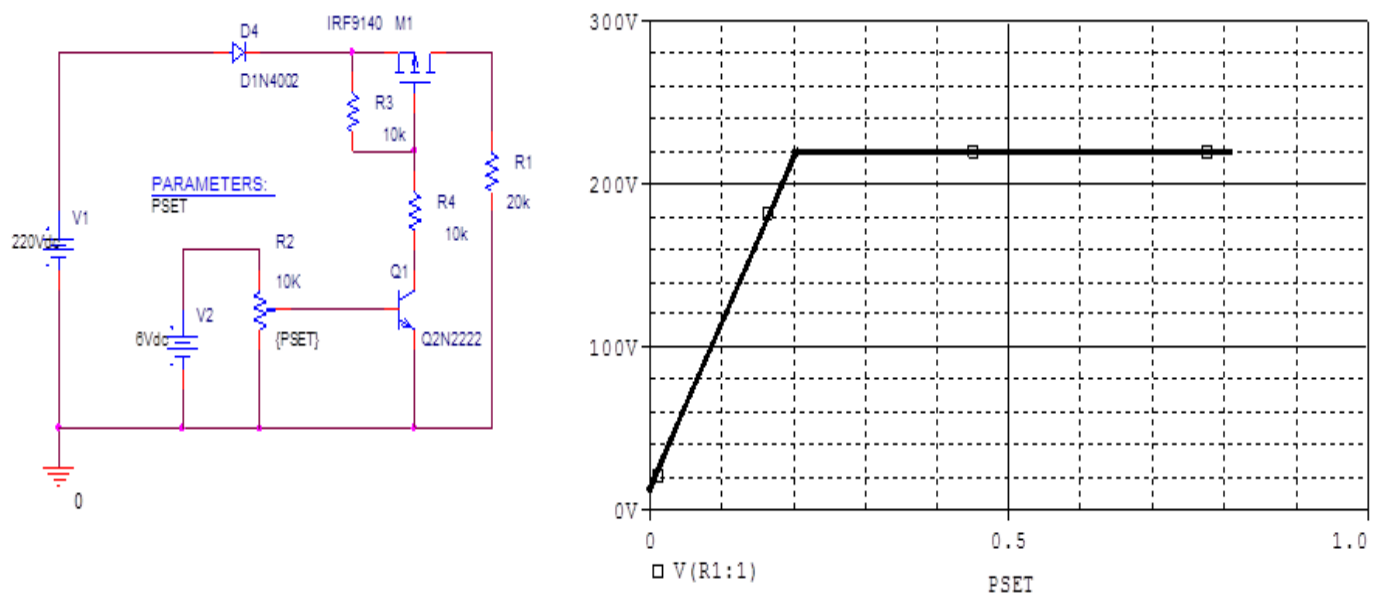

Fig. 8. DC sweep analysis of latch switching circuit.

Next, the circuit was expanded, as shown in Figure 9, to incorporate two pulse generators, and a 6 volts DC VPULSE analysis was done to establish the ON and OFF function of latch (ON, without delay; OFF after delay). The simulation result shows the latch to operate as designed. 


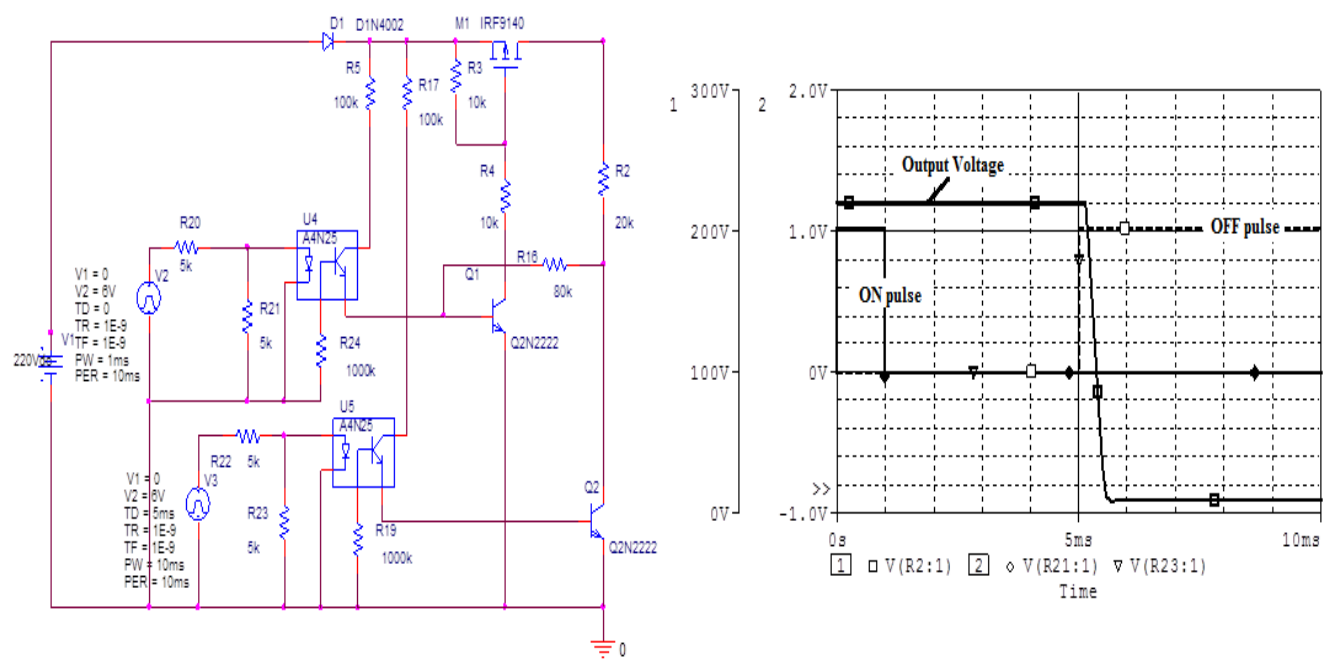

Fig. 9. VPULSE simulation of latch on a 110VDC supply input.

Then, we replaced the 220 DC power with a 220 VAC power and did a Transient analysis, using VSIN and the equivalent test motor impedance, as shown in Figure 10. We found that the first few seconds of the applied voltage, shown in Figure 10a, is indeterminate, which gives us a clue to avoid it by including a phase angle ON delay. We then factored in the calculated thyristor conduction angle delay of 3.2 milliseconds and the result was perfect finish, as shown in Figure 10b.

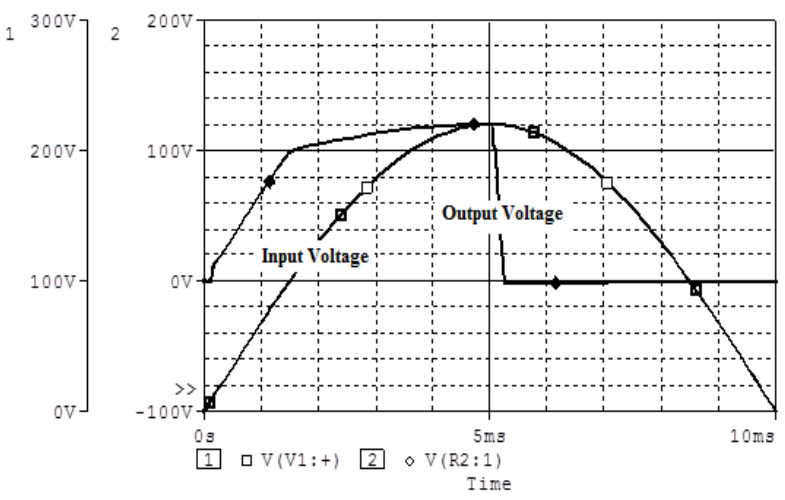

a) At zero angle firing delay
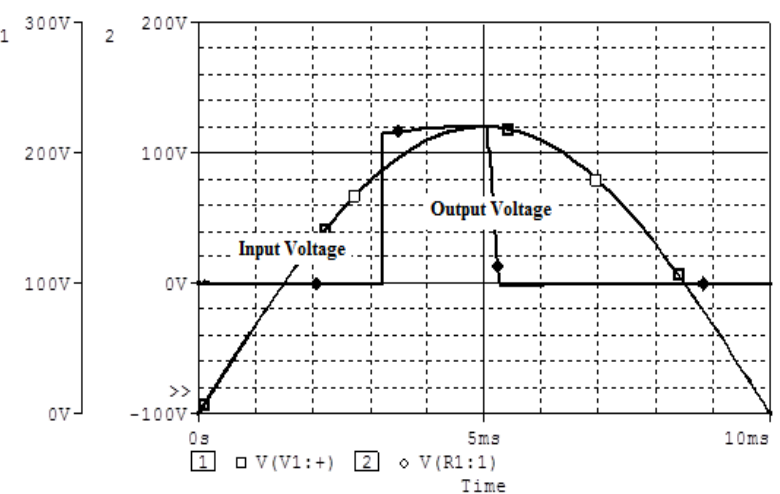

b) At $3.2 \mathrm{~ms}$ angle firing delay

Fig. 10. Simulation circuit of latch using a 220VAC supply input and motor equivalent impedance.

The load voltage and current for a switch off delay of $5 \mathrm{~ms}$ and $8 \mathrm{~ms}$, respectively, are shown in Figures $11 \mathrm{a}$ and $11 \mathrm{~b}$ respectively. 


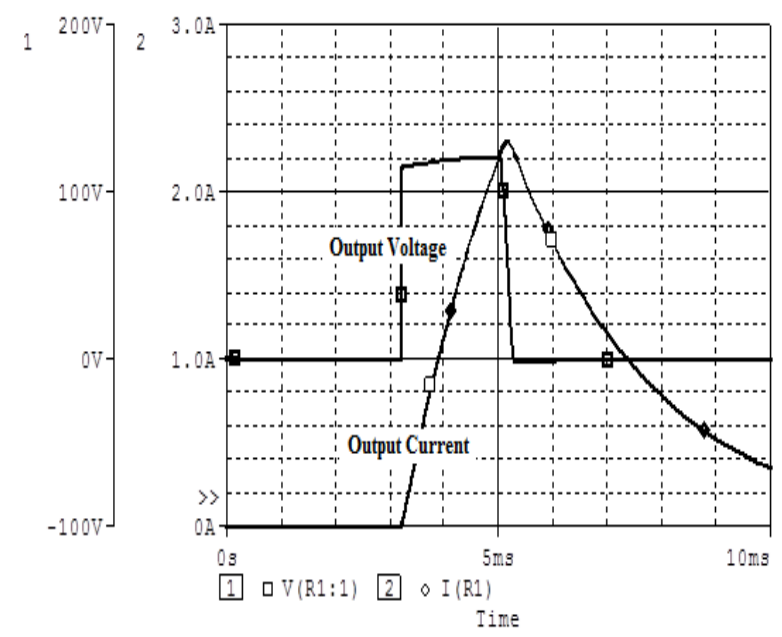

a) At $3.2 \mathrm{~ms}$ angle $\mathrm{ON}$ firing delay and $5 \mathrm{~ms}$ OFF firing delay

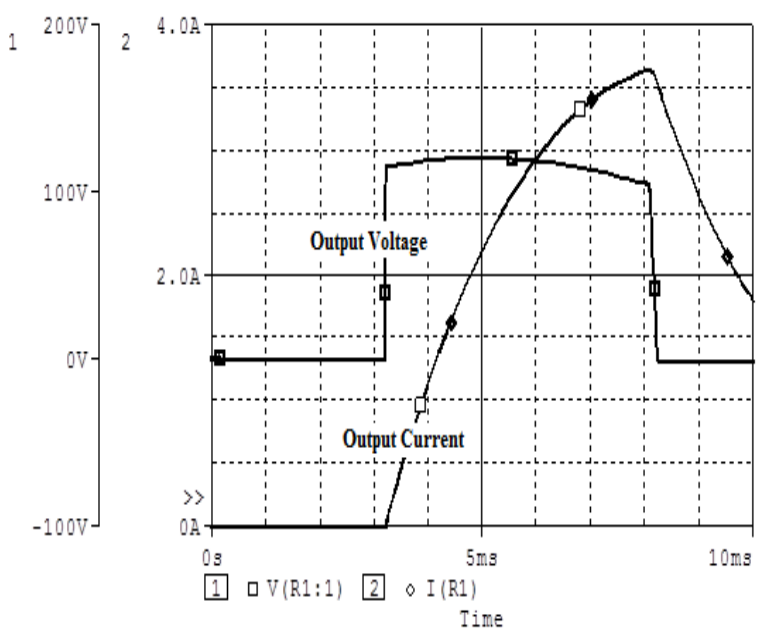

b) At $8 \mathrm{~ms}$ OFF firing delay

Fig. 11. Load voltage and current for a switch delay of $5 \mathrm{~ms}$ And $8 \mathrm{~ms}$.

Finally, an AC sweep analysis of the circuit was done, using VAC to determine the frequency spectrum. The result, shown in Figure 12a, indicates a growth curve that increases very rapidly as the frequency increases.

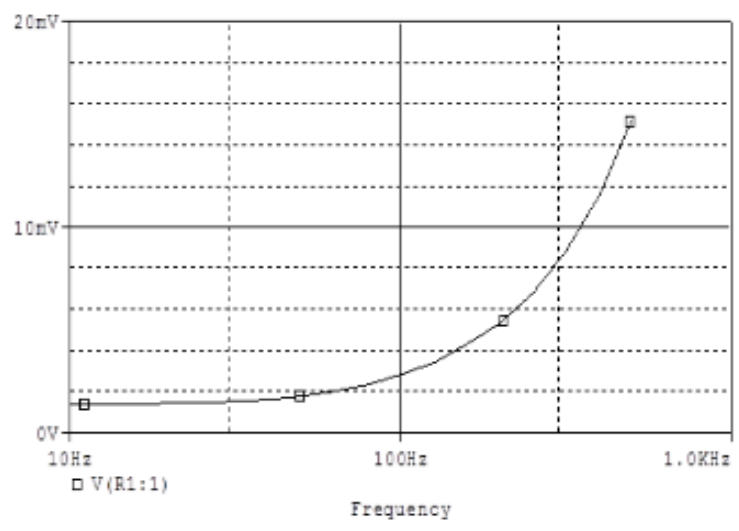

(a)

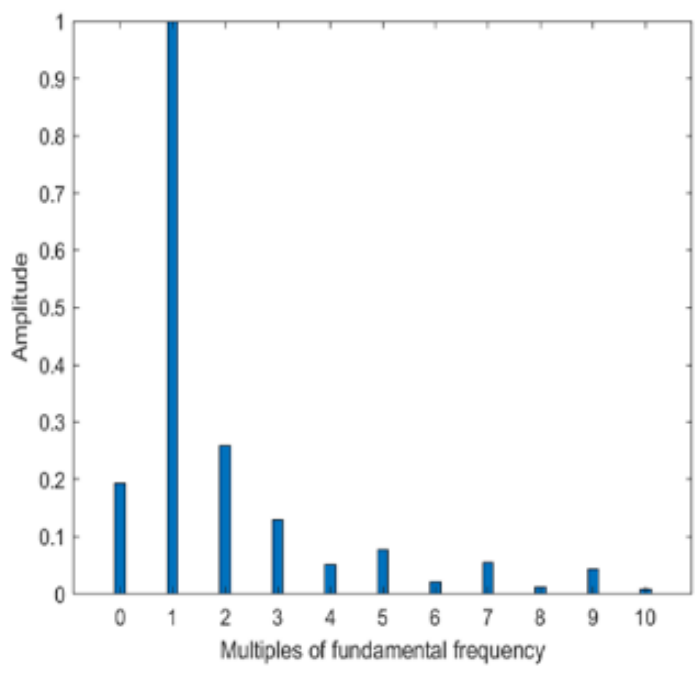

(b)

Fig. 12. Frequency spectrum of the modified pulse width modulated wave.

\subsection{Spectrum representation}

By inspection, the function:

$$
f(t)=[\sin (\omega t+\partial)-\sin (\partial)]
$$

may be analyzed as the sum of two fundamental sine waves;

$$
f(\omega t) \text { of amplitude }(\omega t+\partial) \text { and }
$$

$f(\propto)$ of amplitude $(-\partial)$ at $\propto=\omega t=\partial$ and the two-line spectra Fourier series representation of the function is given as:

$$
f(x)=A_{o}+a_{1} f(t) \mp \sum_{n=2}^{\infty} a_{n} \cos n x d x-B_{o}+b_{1} f(\propto) \mp \sum_{k=3}^{\infty} b_{k} \cos k x d x
$$


The one side spectrum coefficients are found at:

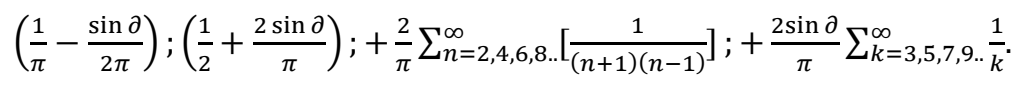

Plotting the bar graph, using MATLAB, we get the frequency spectrum shown in Figure 12b.

The total harmonic distortion, $T H D$, is defined as:

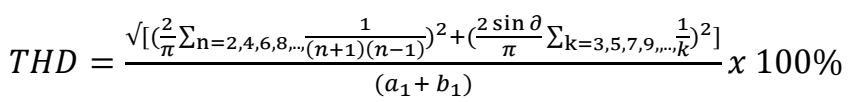

Thus, the $\%$ THD for the Modified PWM speed controller is $=31 \%$

By way of comparison, it is interesting to note that the \%THD for the conventional PWM speed controller would ordinarily be similar to that of:

$$
f(\omega t), \text { or } \% T H D=\frac{\sqrt{\left[\left[\frac{2}{\pi} \sum_{\mathrm{n}=2,4,6,8, \ldots, \overline{(n+1)(n-1)}}\right)^{2}\right]}}{a_{1}} x 100 \%=43 \%
$$

While that for the phase angle speed controller would be similar to that of $f(\propto)$. At $\propto=\pi$.

$$
\% T H D=\frac{\sqrt{ }\left[\left(\frac{2 \sin \partial}{\pi} \sum_{\left.\left.\mathrm{k}=3,5,7,9, \ldots, \frac{1}{k}\right)^{2}\right]}\right.\right.}{b_{1}} \times 100 \%=42.5 \%
$$

which is the same as for the conventional PWM speed controller.

\subsection{Implementing the m-phase firing scheme}

The evolution of a multi-phase induction machine has not progressed beyond the three phase model because the complications of additional phases are not compensated by the slight increase of operational efficiency although optimum rectification and costs are obtained with 6,12 , or more phase transformers [5]. A three phase motor fed with balanced windings produces balanced currents and can be analyzed quite simply by considering only one phase. The connection diagram for a 3-phase implementation of the control circuit diagram is given in Figure 13. Three line transformers T1, T2 and T3 are used to provide the synchronizing phase voltages Vsync1, Vsync2 and Vsync3, respectively, while transformer T4 provides the overall sync voltage as well as the operating circuit low voltages Vcc.

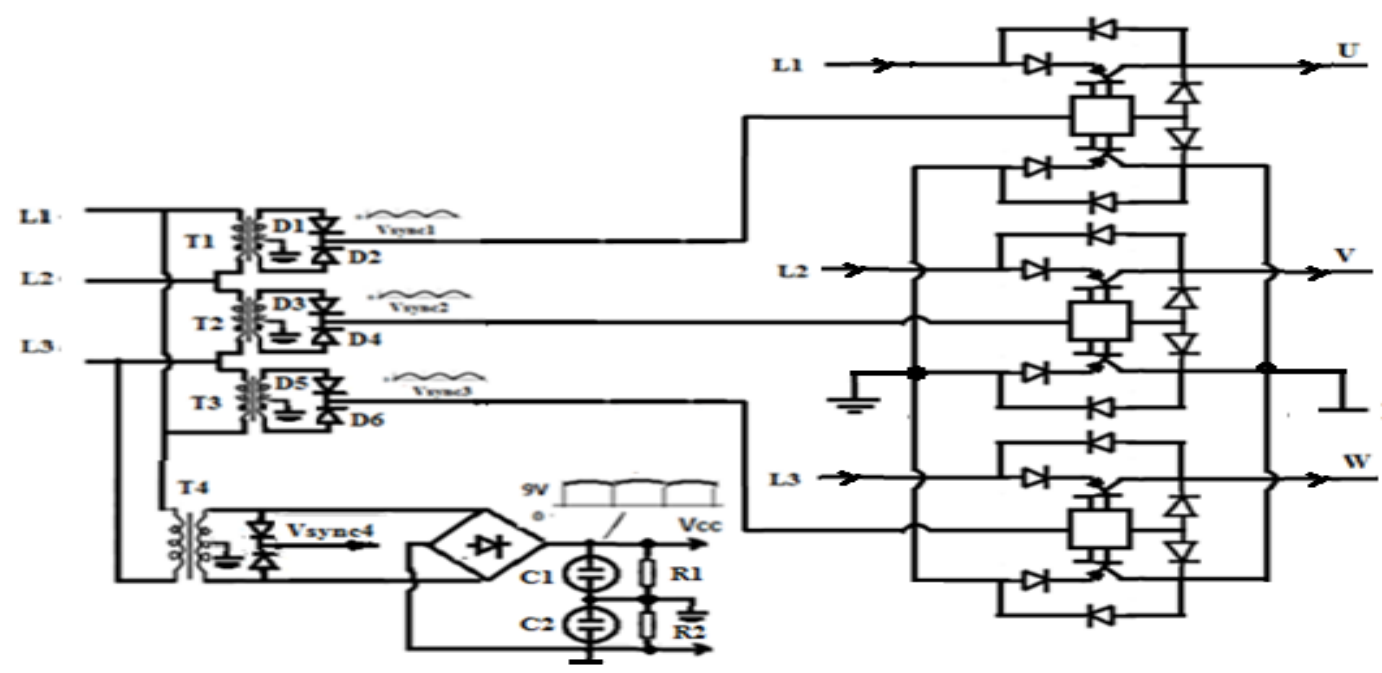

Fig. 13. The 3-phase control connection diagram. 


\section{CONCLUSIONS}

This research presents the modelling and simulation of a modified PWM speed controller for an m-phase power supply. The simulation results, using PSpice, are in correlation with the other aspects of the simulation found using MATLAB. The speed control of the motor is achieved by controlling the firing angle. Although the mutual voltage/frequency control scheme is arguably the best way of controlling the speed of an induction motor under different load conditions, the control scheme becomes complicated and costly since the inverse parallel thyristors connected per phase of the power supply have to be switched on and off repeatedly. In the Modified PWM method, the control scheme is less complicated as each switch is a power transistor switch and are connected in series at each end of the phase load. Phase angle firing control is easily the most cost effective method under similar circumstances. This work shows that by using the Modified PWM firing technique the speed of an m-phase induction motor can be controlled more effectively and reliably.

\section{REFERENCES}

[1] Thaler, G., Wilcox, M., Electrical machines, John Wiley \& Sons Publishers, New York, 1966.

[2] Lipo, T., Jezernik, K., AC motor speed control, Chapter 15, http://www.ro.feri.uni-mb.si/ACmotor book, 2002, (06.2015).

[3] Ilango, B., Krishnan, R., Suramanian, R., Sadasivam, S., Firing circuit for three phase bridge rectifier, IEEE Transactions On Industrial Electronics And Control Instrumentation, vol. 25, no. 1, 1978, p. 45-49.

[4] Barr, M., Introduction to pulse width modulation, Pdf. 2001. (http://www. Allaboutcircuits.com, 2015, (06.2015).

[5] Watson, J., Semiconductor circuit design, The Institute of Physics, Adam Hilger Publishers Ltd, Bristol, 1976 [6] Abramowitz, H., Phase-control alternatives for single-phase AC motors, Articl1.pdf---Power Systems World 2003.

[7] Sen, T., Bhattachrjee, P., Bhattcharya, M., Design and implementation of firing circuit for single-phase converter, International Journal of Computer and Electrical Engineering, vol. 3, no. 3, p. 368-374.

[8] Lu, X., Chen, S., Wu, C., Li, M., The pulse width modulation and its use in induction motor speed control, IEEE Journal, Fourth International Symposium on Computational Intelligence and Design, 2011.

[9] Peter, G., Design Of single phase fully controlled converter using cosine wave crossing control with various protections, International Journal of Engineering Science and Technology, vol. 2, no. 9, 2010, p. 4222-4227.

[10] Http://www.eas.uccs.edu/ece2610)_Chapter 3.pdf. (04.2018).

[11] Hui, L.M., Basic-pulse width modulation, http:/tutorial.cytron.com.my, 2012, (06.2015).

[12] Tang, P.C., Lu, S.S., Wu, Y.C., Microprocessor based design of a firing circuit for three-phase full-wave thyristor dual converter", IEEE Transactions On Industrial Electronics, vol. 29, no. 1, 1982, p. 67-73.

[13] Http://www.machinedesign.com/motorsdrives/basics-motor-nameplates, (04.2018). 